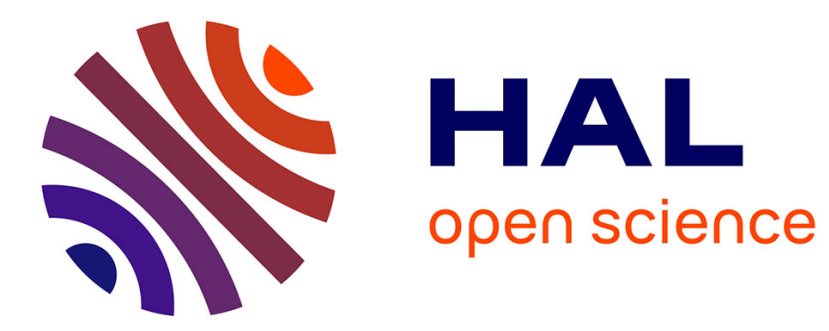

\title{
Learning about reflection from the student
}

Helen Bulpitt, Peter J. Martin

\section{To cite this version:}

Helen Bulpitt, Peter J. Martin. Learning about reflection from the student. Active Learning in Higher Education, 2005, 6 (3), pp.207-217. 10.1177/1469787405057751 . hal-00571935

\section{HAL Id: hal-00571935 https://hal.science/hal-00571935}

Submitted on 1 Mar 2011

HAL is a multi-disciplinary open access archive for the deposit and dissemination of scientific research documents, whether they are published or not. The documents may come from teaching and research institutions in France or abroad, or from public or private research centers.
L'archive ouverte pluridisciplinaire HAL, est destinée au dépôt et à la diffusion de documents scientifiques de niveau recherche, publiés ou non, émanant des établissements d'enseignement et de recherche français ou étrangers, des laboratoires publics ou privés. 


\section{Learning about reflection from the student}

\author{
HELEN BULPITT \& PETER J. MARTIN University of Essex, UK
}

Copyright (C) 2005 The Higher

Education Academy and

SAGE Publications (London,

Thousand Oaks, CA and

New Delhi)

Vol 6(3): 207-217

DOI: $10.1177 / 1469787405057751$

ARTICLE

\begin{abstract}
Reflection, in a classroom setting, presents educators with a method for narrowing the theory-practice gap. Material from the practice environment can be brought into the classroom and used as the substance of learning from experience. Enabling students to understand and value reflection is an essential part of this process. It is also a process which should be a carefully considered and managed part of the curriculum. This article reports on a small-scale participatory action research project that examines the development of reflection from the perspective of the student.
\end{abstract}

KEYWORDS: reflection, reflective practice, student

experience, student support, supervision, teaching

\title{
Developing reflection in professional education
}

Reflection has a long history with reference in the work of Dewey (1933), Polanyi (1966) and Habermas (1971). The recent interest within the field of professional education can be sourced to authors such as Kolb (1984), Schön (1983, 1987), Mezirow (1981, 1990), Boud et al. (1985) and Moon (2000). These authors provide a contemporary view of reflection and establish a relationship between reflection and professional education. Reflection in Mezirow's $(1981,1990)$ work is a means by which practitioners can challenge underlying assumptions in order to develop perspective transformation. The ideal learning conditions for this to occur are facilitative, with value conflict being handled effectively and underpinned by the principles of androgogy (Mezirow, 1990). Schön's work (1983, 1987) concerns the significance of reflection within the professions. The work explores the operation of reflection and how it can be developed and coached within students. Schön describes three type of coaching: joint experimentation, follow me and hall of mirrors (Schön, 1987: 295). Each model is performed distinctly and with specific purpose. Eraut (1994: 146), however, is critical of Schön for failing to satisfactorily explain how these forms of coaching are delivered in the real 
world. Boud et al. (1985) and Boud and Walker (1993) describe the initial development of a model of reflection and its subsequent modification. Boud and Walker's (1993) work identified that internal barriers (selfawareness, preparedness, intent, etc.) and external barriers (support systems, inadequate preparation, etc.) will impact upon the ability of the learner to reflect. Mezirow $(1981,1990)$ and Boud and Walker's (1993) work can be compared to that of Wildman and Niles (1987, cited by Moon, 2000: 68). These authors recognized that reflection created problems for the learner in balancing the abstract with reality. The conditions necessary to bolster reflection were identified as support, time and space and a collaborative environment.

In recent years there has been considerable interest in the role of reflection within professional education. Reflection is found within health, social care and education curricula where it is described as an essential part of professional practice (e.g. GSCC, 2003; ILTHE, 2003: 5; NMC, 2002: 21; Parsell et al., 1998). Reflection has become a significant component of professional education at both pre- and post-qualifying levels in nursing, social work and education. Moon (2000) argues that this is partly because practice in these professions is often rapid, with proof of expertise based on outcome rather than underpinning knowledge - 'Action is what counts' (Moon, 2000: 55). In addition, these and similar professions rely less on factual detail and more on interpretation and understanding of a complex situation (Moon, 2000: 55). The aim is 'wise action in a social context of judgement about what is right' (Boud et al., 1985: 145). This brief overview of the current literature suggests that there are a number of significant gaps in knowledge concerning the facilitation of reflection within an educational environment. These gaps include the student experience of, and meaning attributed to, reflection; strategies by which reflection is facilitated; and the application of participatory research methods as an effective means of exploring the phenomenon. There is limited research concerning the facilitation of reflection in a training environment.

The research presented in this article examines the development of reflection within a counselling training environment. The study explores the experience of reflection and the meaning students attribute to these experiences. A participatory action research method was selected as it is congruent with the principles espoused by both adult education in general and counselling training in particular (Kemmis and McTaggart, 1988; Schwartz and Ogilvy, 1979). Participatory action research is also consistent with Brookfield's concept of critical reflection (1987) and is, according to Carr and Kemmis (1986), an effective means of bridging the theorypractice gap through teacher-as-researcher. Very little research on reflection 
was identified that adopted participatory action research despite the apparent close association. The current project was one small-scale attempt to do so and to raise some of the issues that may be inherent in such a project. The student experience, reported through this research, raises issues about the delivery of reflection within a curriculum. The findings and implications are of relevance to those working within formal and informal educational environments where students are assisted to develop reflection. The terms reflection and reflective practice are used interchangeably in this article.

\section{Method}

Eight second-year students, a complete cohort, undertaking a Diploma in Pastoral Counselling in 2002 were invited by the researcher (HB) to participate in the study. Data were collected in a classroom in which a group of students engaged in discussions about reflection under the facilitation of a course leader. Data included in this study derived from six discussions, which were audio-recorded and transcribed by the researcher. The authors acknowledge that the sample, method of selection and relationship to the researcher raise issues concerning trustworthiness and generalizablity of the final dataset.

In the first session, the aim of the project was introduced. Students were invited to participate in exploring ways in which their curriculum could be adapted in order to enhance opportunities for the development of reflection. It became apparent that the students were unfamiliar with the term reflection and wanted time to explore the concept in theory and practice. Data produced in these initial discussions led to a review of the research procedures. It was decided that the focus would be on the initial exposure to reflection rather than a more substantial examination of the subject. This is congruent with McCleod's (1994) assertion that the research processes in participatory research are responsive to, and shaped by, contributions from each participant. Subsequent sessions enabled the group to explore their understanding of reflection and its relevance within their counselling practice. In the final session (Discussion 6) the group reviewed the discussion so far and compiled a list of possible ways forward for their curriculum.

The data gathered through the extended exploration of meaning were examined. Preconceived ideas and assumptions about reflection were bracketed (Ashworth, 1996; Husserl, 1931) in order that the essence (Moustakas, 1994) could emerge with the group's own constructions and meanings intact. Data were examined for themes through the application of techniques associated with grounded theory (Strauss and Corbin, 1998). 
The analysis attempted to derive a thick description (Geertz, 1973) of the students' understanding rather than interpretation, the aim being to derive meaning of the concept to these people at this time, rather than moving to a further level of abstraction and generalization, as might be expected in a purely grounded theory approach.

\section{Findings}

The data derived from the discussions raised issues for both theory and practice. Unbeknown to the students who contributed, there was a high level of concurrence with the descriptions of reflection found in the literature. The transcripts were scrutinized and emergent categories examined.

The essence of reflection was distilled and formulated into a single statement agreed by the group.

Reflection is a process triggered by an unsettled sensation, either by choice or by chance, which has the potential to be beneficial to counsellors in their counselling practice. It has a meta or set-apart quality about it. It takes the form of an internal conversation and comprises a process of anticipating the consequences of the available courses of action in order to make an informed choice, and occurs before, during or after the triggering event. It involves emotions, learning, thinking, daydreaming, instincts, pondering, gut feeling and awareness, and is influenced by our spirituality and our personality. It can be enabled by external input, such as supervision or discussion with others. The process changes you and, at best, brings peace and resolution to the unsettled sensation, but it also carries with it the danger that its very set-apartness may be detrimental to a counselling process that depends upon congruence and being fully present in the counselling encounter.

The findings were grouped into three categories addressing three questions. One, what is reflection? Two, how do counsellors reflect? Three, how does reflection relate to other processes? Quotations from student participants are coded, for example, 3TI. The first number represents the discussion number (that is, 1-6); the two letters are not initials, but identify the student who is being quoted.

\section{What is reflection?}

The group described reflection as an opportunity to look at an event from a different perspective. Reflection had a quality of set-apartness from the immediate environment and included anticipating the consequences of various courses of action.

It's about being detached enough from yourself to watch what you are doing. (2TI) 
In terms of the meaning of reflection: it's replaying a conversation or an event and reflecting on the impact of it on myself or the other person. (3KX)

There was recognition that reflection changes you in some way, and that the ending is characterized by a renewed sense of peace or acceptance.

I put the aim of reflection as 'seeing things as they are' and being transformed or changed. $(2 \mathrm{NH})$

\section{How do counsellors reflect?}

Students recognized that reflection is a process and it can occur before, during or after the event. It is triggered by some kind of unsettled feeling, or lack of peace.

The first thing that comes is a feeling. (2QB)

That feeling of not feeling comfortable. (3QB)

Reflection was described as being an informal and a formal process. There was a shared sense that formal reflection involved conscious activity. This might include discussion with peers/supervisors, writing or thinking. Informal reflections were uninvited, and not always welcome.

With the informal, it's more emotional. There's a lack of control. The formal is easier to cope with. (2QB)

I just do it . . . I reflect on things a lot. Yes, sometimes it's beneficial, sometimes it's not and I think if it's a worrying type of reflection it is not beneficial. I wish I could just leave it, but it's quite involuntary. (3KX)

Reflection was described as something that cannot always be turned on and off at will, and was not always comfortable.

The things that go on in my head - you can become preoccupied with. (5KN)

The freedom to actually not reflect, not to sort of analyse; that would be ideal. (5QB)

Reflection was described as a meta or set-apart process that occurred in the background whilst students were engaged in some other activity. Students expressed concern that this would prevent them from paying full attention to the client.

In counselling, if I reflect on my own, then it's not being present with the client which is what I need to do. (5NH)

Students described reflection as a developmental stage. Some believed that sufficiently experienced counsellors would no longer need to reflect. However, others saw an ongoing role for reflection in professional practice. 
In counselling, you get to a place where you do it automatically without thinking. Some people, even without training, do it. (3FG)

I think the reflection just changes. At the beginning there's lots of things to practise and then you become aware. The reflection then changes, but doesn't become any less. (4KX)

\section{How does reflection relate to other processes?}

Reflection was linked, by the group, to a number of other experiences, the two most often referred to being emotions and learning. Other related processes that emerged were thinking, spirituality and personality, as well as some more intuitive processes, including instinct, gut feeling, daydreaming, praying and pondering.

\section{Discussion}

The students felt that reflection could create change, leading to growth and transformation, all of which are supported in the literature. However, the findings also raise a number of other issues not often addressed in the literature.

- Reflection is not always a positive experience, and cannot always be turned on and off at will.

- Reflection is a much broader experience than purely a rational, thinking process. It may involve, for example, feeling, instincts and spirituality.

- Reflection has a meta quality that may be detrimental to a counselling process that depends on being fully present.

- Guided reflection and reflection within supervision, are variable processes that may or may not be helpful.

\section{Reflection as an involuntary, problematic experience}

It's not unconditionally positive. The reflection sometimes plays on my mind. $(5 \mathrm{KX})$

Boud and Walker (1993) note that reflection can be powerfully prompted by discrepancies or dilemmas that the individual is forced to confront. The findings indicate that students were disturbed by the unexpected emotional impact of thoughts and feelings emerging through reflection. Educators who encourage students to reflect should also make them aware that the process can be distressing. Furthermore, the students in the study indicated that, once activated, reflection could not always be turned off. With experience, practitioners learn to control their reflective processes in a more systematic manner, though not at every occasion. Educators should be 
aware, when using reflection in a student group, that events may quickly go beyond that which is controllable. The power of the students' experience within the study should not be understated. Educators can be effective in assisting students to engage with reflection in order for them to better understand and learn from their experiences. In the same way as students might be taught to engage and disengage with clients with whom they are working, students should be taught to disengage with reflection.

\section{Reflection as a holistic process}

As I'm doing this, I'm thinking that the potential is that it can completely change your view. (2QB)

The findings suggest that the students embarked upon unique journeys over which they had little control. It was this journey or process over time that was captured through the data. Students described reflection as a 'cathartic thing' (2OQ), an experience that led to a point of acceptance. Teaching reflection through the medium of a model (e.g. Boud et al., 1985: 36) or as a structured guided reflection (Johns, 1994) may not, necessarily, encompass the depth of engagement demonstrated by this student cohort, particularly those first encountering reflection. Notably, Boud et al. (1985: 21) acknowledge the importance of the affective component as both enhancing and constraining reflection. The students perceived reflection to be a significant phase in their development as professional practitioners, a view supported by Moon (2000: 88).

However, the students expressed concern about their preparedness to engage in reflection. This may be related to Benner's (1984) work, which demonstrates how novice practitioners seek clear sets of rules by which to work. As the person develops skills and moves toward expert practice s/he is able to deviate from the rule-bound functioning and engage in practice shaped by their knowledge and skills within parameters set by themselves. At this early stage students sought clear rules and boundaries by which they might engage in reflection.

Reflection is a cumulative process that enables practitioners to build a store of practice knowledge on which to draw. Boud et al. (1985) describe the term 'association' as the relating of previous experiences, in a systematic manner, to the current situation. Furthermore, Schön recognizes the significance of previous experience within reflection in action where the practitioner relies upon a repertoire of images of contexts and actions (1985: 29). For the novice, without a range of experience on which to draw, this may appear as frightening and uncharted territory. This presents a challenge to educators in the recognition, by student and educator alike, 
of transferable skills. Educators have the opportunity to encourage students to value all their prior experiences and not only those directly related to their new profession.

\section{Reflection and apartness}

In terms of the meaning of reflection: it's replaying a conversation or an event and reflecting on the impact of it on myself or the other person. (3KX)

Students recognized that reflection is triggered by an experience. This is congruent with most literature (for example, Atkins and Murphy's (1993: 1190) review). The student group recognized that reflection within the counselling relationship meant a cognitive absence from the client. Schön (1987: 26) described reflection in action as a process that occurred in the 'action present', where a difference could still be made to the situation upon which one was reflecting. Benner (1984: 32) describes the intuitive grasp demonstrated by experts who are apparently able to focus on the accurate region of the problem 'without wasteful consideration of a large range of unfruitful, alternative diagnoses and solutions'. Such rapid and complete comprehension of the situation is not available to the novice, which presents a potential barrier to reflection if it is not addressed directly by educators.

\section{Guided reflection and reflection within supervision}

Not that my supervisor is wrong; they felt like good ideas at the time . . . but, sometimes, they [the clients] need the space. To try and manufacture the conversation to come round to what my supervisor thinks I should include doesn't seem quite right. (5OQ)

Educators seeking to assist students to reflect may provide supervision and guided reflection as part of a learning package. Johns (1994: 119) recommends the line manager as an appropriate person to supervise guided reflection and argues that guidance helps to make practitioners aware of the qualities (awareness, curiosity, reflectiveness and commitment) necessary for effective work (p. 128). However, some of the students indicated ambivalence toward supervision as a context for reflection, describing supervision as a hurdle that is separate from the real world in which they practise. The group did not, unanimously, see supervision as a positive aspect of reflection.

Johns (1994: 111) describes a structured approach to reflection under the tutelage of an expert supervisor that involves the use of a model of structured reflection, supervision and a diary. Educators' use of supervised reflection is undoubtedly valuable, but students also need to develop trust 
in their own ability to reflect as an aspect of professional practice. If supervisors do not have a clear understanding of their role and function, supervision may encourage the abdication of responsibility by inexperienced practitioners.

This study, whilst acknowledging limitations, suggests that a guided approach is not the single ideal. Schön's description of the role of the coach (1987: 17) may provide a useful insight into overcoming supervisory problems. Coaching enables students to develop reflection with the support of a coach who maintains an environment in which the student can best learn. The research suggests that professional educators should examine how Schön's model of coaching could be applied within the real world environment of professional practice. In Schön's somewhat ideal world, the student has a supervisor whom they can work alongside, observing and developing their own skills. Such a relationship is described as occurring in an environment of order and calm. This is far from the real world of practice as experienced by many in health care, social care or education. The role adopted by the researcher corresponded with that of the coach in the development of reflection. In consequence, the research implicitly examines Schön's conception of the development of reflection. However, it is recognized that it was not to examine this issue that this research was designed.

\section{Conclusions and implications for educators}

The findings suggest that educators should concern themselves more with the development of a reflective environment than teaching students how to reflect. This might account for the slow adoption of reflection within education. Where reflection, as a prescribed activity, is encouraged as an organizational activity, the outcome may be limited. With the active and committed support of a coach, however, students may naturally adopt a reflective stance to their work. The results of this study have implications for educators:

- Reflection is not always a positive experience for students. It cannot always be turned on and off at will and can be disturbing. This should be acknowledged with student groups and provision made for appropriate support.

- Reflection is a much broader experience than purely a rational, thinking process. It may involve, for example, feeling, instincts and spirituality. This should also be recognized within curricula and students should be encouraged to examine the fruit of reflection in many contexts and arenas. 
- Reflection has a meta quality that may be detrimental to a process such as counselling, that depends on being fully present. The consequences of being even momentarily apart from the client should be discussed and appropriate strategies developed to manage the process.

- Guided reflection and reflection within supervision are variable processes that may or may not be helpful. Educators should enable the student to explore strategies and adopt those that are congruent with the individuals needs.

This research has explored the development of reflection within one cohort of students undertaking a vocational training programme. Criticism concerning contamination of data and bias within the research design and problems of being a researcher-practitioner are recognized and acknowledged. The study indicates that there is need for further research in this area. More rigorous research that adopts a participatory action research approach will add to understanding the optimum methods of delivering reflection within professional curricula.

\section{References}

ASHWORTH, P. (1996) 'Presuppose Nothing! The Suspension of Assumptions in Phenomenological Psychological Methodology', Journal of Phenomenological Psychology $27(1): 1-25$.

ATKins, S. \& MURPHY, K. (1993) 'Reflection: A Review of the Literature', Journal of Advanced Nursing 18: 1188-92.

BENNER, P. (1984) From Novice to Expert. Menlo Park, CA: Addison Wesley. BOUD, D. \& WALKER, D. (1993) 'Barriers to Reflection on Experience', in D. Boud,

R. Cohen and D. Walker Using Experience for Learning, pp. 73-86. Buckingham: Open University Press.

BOUd, D., KEOGH, R. \& WALKER, D. (eds) (1985) Reflection: Turning Experience into

Learning. London: Kogan Page.

BROOKfield, S. D. (1987) Developing Critical Thinkers. San Francisco: Jossey-Bass. CARR, A. \& Kemmis, S. (1986) Becoming Critical: Education and Action Research. London:

Falmer Press.

DeWey, J. (1933) How We Think. Boston: D. C. Heath \& Co.

ERAut, M. (1994) Developing Professional Knowledge and Competence. London: Routledge. GeERTZ, C. (1973) The Interpretation of Culture: Selected Essays. New York: Basic Books. GSCC (2003) Social Work Post Qualifying Education Framework: Response to Consultation. London:

General Social Care Council.

Habermas, J. (1971) Knowledge \& Human Interests. London: Heinemann.

HuSSERL, E. (1931) Ideas (trans. W. R. Boyce Gibson). London: George Allen \& Unwin.

ilthe (2003) Imagining a Different Future - Working Paper II. London: Institute for Learning and Teaching in Higher Education.

Johns, C. (1994) ‘Guided Reflection’, in A. Palmer, S. Burns and C. Bulman (eds)

Reflective Practice in Nursing, pp. 110-30. Oxford: Blackwell Science.

Kemmis, s. \& mCtagGart, R. (1988) Action Research Planner. Geelong, Australia:

Deakin University Press. 
KOLB, D. (1984) Experiential Learning as the Science of Learning Development. Englewood Cliffs, NJ: Prentice Hall.

MCLeOD, J. (1994) Doing Counselling Research. London: Sage.

Mezirow, J. (1981) 'A Critical Theory of Adult Learning and Education', Adult

Education 32(1): 3-24.

mezirow, J. \& Associates (1990) Fostering Critical Reflection in Adulthood. San Francisco: Jossey-Bass.

MOON, J. (2000) Reflection in Learning and Professional Development. London: Kogan Page.

Moustakas, c. (1994) Phenomenological Research Methods. London: Sage.

NMC (2002) Requirements for Pre-registration Nursing Programmes. London: Nursing \&

Midwifery Council.

PARSEll, G., Spalding, R. \& Bligh, J. (1998) 'Shared Goals, Shared Learning:

Evaluations of a Multiprofessional Course for Undergraduate Students', Medical

Education 32: 304-11.

polany i, M. (1966) The Tacit Dimension. New York: Doubleday.

SCHÖN, D. (1983) The Reflective Practitioner. San Francisco: Jossey-Bass.

SCHÖN, D. A. (1987) Educating the Reflective Practitioner. San Francisco: Jossey-Bass.

SChWARTZ, P. \& OGIlvy, D. (1979) The Emergent Paradigm: Changing Patterns of Thought and

Belief ( Analytical Report 7 Values \& Lifestyle Programme). Menlo Park, CA: SRI

International.

Strauss, A. \& CORBin, J. (1998) Basics of Qualitative Research: Techniques and Procedures for

Developing Grounded Theory (2nd edn). London: Sage.

Wildman, T. \& Niles, J. (1987) 'Reflective Teachers: Tensions between

Abstractions and Realities', Journal of Teacher Education (July-August): 25-31.

\section{Biographical note}

HELEN BULPIT T is a Learning and Teaching Adviser with the Higher Education Academy Health Sciences and Practice Network. She is also a teacher in adult education, as an Associate Lecturer with the Open University, and is an accredited counsellor, counselling trainer and supervisor. She is currently undertaking her $\mathrm{PhD}$ at the University of Essex, researching the practice of supervision in mental health professions.

Address: Department of Health and Human Sciences, University of Essex, Wivenhoe Park, Colchester CO4 3SQ, UK. [email: hlbulp@essex.ac.uk]

PETER J. MARTIN is a Senior Lecturer in the Department of Health and Human Sciences at the University of Essex. He has a professional background as a mental health nurse and has worked as a practitioner and as a manager. He has an interest in reflective practice and supervision in both educational and practice settings. Currently, he is scheme leader for Professional Doctorates offered through the University of Essex.

Address: Department of Health and Human Sciences, University of Essex, Wivenhoe Park, Colchester CO4 3SQ, UK. [email: petem@essex.ac.uk] 